TP Periodica Polytechnica Mechanical Engineering

61(4), pp. 255-260, 2017

https://doi.org/10.3311/PPme.10431

Creative Commons Attribution (i)

\title{
PSI and TOPSIS Based Selection of Process Parameters in WEDM
}

\author{
Sunny Diyaley ${ }^{1}$, Pramod Shilal ${ }^{2}$, Ishwer Shivakoti ${ }^{1}$, \\ Ranjan Kumar Ghadai ${ }^{1}$, Kanak Kalita ${ }^{3 *}$
}

RESEARCH ARTICLE

\begin{abstract}
Wire electric discharge machining (WEDM) is a nontraditional machining process for machining conductive materials with complex and intricate shapes with a high surface finish and dimensional accuracy. The decision making for the selection of the best set of combinations of input process parameters is a major challenge. Therefore a proper optimization tool should be used for the optimal selection of process parameters. The resent work deals with the comparative study of Preferential Selection Index (PSI) and Technique for Order of Preference by Similarity to Ideal Solution (TOPSIS) for the selection of process parameters during machining of EN31 tool steel. Four input parameters- Pulse on Time $\left(T_{\text {on }}\right)$, Pulse off Time $\left(T_{\text {off }}\right)$, Servo Voltage (SV) and the Wire tension (WT) are considered. Surface roughness and material removal rate are the measured output responses. Taguchi L9 orthogonal array is used for developing the experimental design. Three levels of each control factor are considered. The results show that a single parameter alone does not have a significant influence on the output responses. Thequality of the output responses depends on the combination of the various set of input parameters. The best set of combination suggested from the current input parameters for machining of EN31 Tool Steel by Wire EDM Process is found to be Pulse on Time $\left(T_{\text {on }}\right)=15 \mu \mathrm{s}$, Pulse Off Time $\left(T_{\text {off }}\right)=35 \mu \mathrm{s}$, Servo Voltage $(S V)=40 \mathrm{~V}$ and the Wire tension $(W T)=5 \mathrm{~kg} f$ from both PSI as well as TOPSIS techniques. Confirmation experiments are performed to validate the optimal results.
\end{abstract}

\section{Keywords}

WEDM, Pulse on Time $\left(T_{\text {on }}\right)$, Pulse off Time $\left(T_{\text {off }}\right)$, Servo Voltage (SV), TOPSIS, PSI

\footnotetext{
${ }^{1}$ Department of Mechanical Engineering, Sikkim Manipal Institute of Technology, Majhitar, India

${ }^{2}$ Advanced Technical Training Centre, Bardang, India

${ }^{3}$ Department of Aerospace Engineering \& Applied Mechanics, Indian Institute of Engineering Science and Technology, Shibpur, India

*Corresponding author, e-mail: kanakkalita02@gmail.com
}

\section{Introduction}

With the development of technology, more challenging problems are being faced by the technologists in the field of manufacturing. The difficulty in adopting the conventional manufacturing processes can be attributed mainly to the machining principle that requires a cutting tool which must be harder than the material of the work-piece. New materials which have a high strength-to-weight ratio, heat resistance and high hardness are tough to machine and also timeconsuming by conventional methods. Hence, advanced machining processes are being developed to overcome these difficulties. These newly developed techniques provide a very high accuracy and can machine complexly shaped surfaces. These processes, however, are not meant for replacing the conventional processes but are a supplement to them.

Optimization and selection of proper process parameters play a vital role in any of the manufacturing or metal processing industries. Selection of proper cutting conditions is essential for efficient machining. Improper selection of machining parameters leads to several adverse effects during machining. Optimization technique provides a proper selection of cutting parameters. Many research attempts have been made to select the proper cutting parameters in WEDM. In past response surface methodology has been used to enumerate the relationship between input and output responses in the WEDM process and the effects of input process parameters on MRR and surface roughness were studied by Gowd et al. [1]. Tilekar et al. [2] investigated to analyze the effect of process parameters on surface roughness and kerf width of aluminium and mild steel. Taguchi method opted for the optimization. Spark on time, spark off time, input current and wire feed rate were used as input parameters and ANOVA results showed that spark on time and input current have statistically significant effect in the case of aluminium and mild steel respectively. Dabade and Karidkar [3] analyzed the machining conditions of material removal rate, surface roughness and kerf width and dimensional deviation during WEDM of Inconel 718 using Taguchi technique. It was observed that pulse on time was the most influencing factor. Patel et al. [4] applied AHP/TOPSIS 
technique for the selection of optimal process parameters in the WEDM process in which pulse on time, pulse off time, flushing pressure, wire tension, servo voltage, wire feed are taken as input process parameters. Material removal rate, kerf width and surface roughness are considered as output responses. Saha et al. [5] applied feed-forward neural network model to correlate pulse-on-time, pulse-off-time, peak current and capacitance with the output parameters cutting speed and surface roughness during wire electrical discharge machining of tungsten carbide-cobalt (WC-CO) composite material. Patel et al. [6] applied analytical hierarchy process (AHP) and multi-objective optimization by ratio analysis (MOORA) in the WEDM process while machining EN 31 alloy steel. The study proved the applicability of these two methods. Ardeshir and co-workers [7-9] have used the fuzzy-Topsis to select a suitable site for building a bridge on a river in Iran [9]; for making risk estimation due to high rise buildings [8] and water tunnels [7].

From the available literature, it is revealed that TOPSIS and PSI have not been applied for the selection of most suitable process parameters in the WEDM process. Thus, in the current paper, these two straightforward and easy to implement multi-criteria decision analysis methods are applied during an experimentation of WEDM process in machining of EN31 tool steel. The basic workflow followed in the current research work is highlighted in Fig. 1.

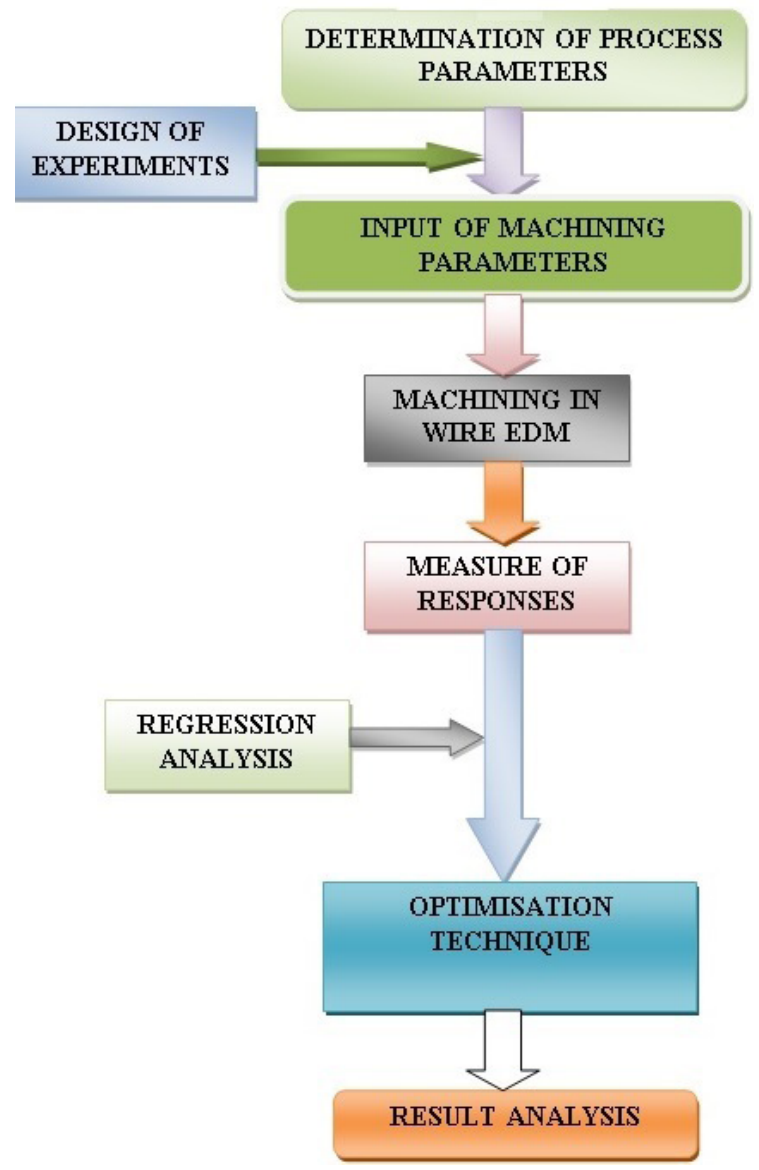

\section{Experimental details}

Round EN-31 steel bars of diameter $14.8 \mathrm{~mm}$ is selected as workpiece material. EN31 Tool Steel is chosen as the material for the study and optimization due to three primary reasons- (1) Not much research has been done for the study of EN31 Tool Steel in wire EDM process. (2) It is one of the most versatile tool steel used for various purposes. (3) Due to its poor machinability. The chemical composition of the EN-31 steel is included in Table 1. ELECTRONICA SPRINTCUT-734 with 4 axes CNC guideways, flushing pressure of $12 \mathrm{kgf}$, maximum wire feed $12 \mathrm{~m} / \mathrm{min}$, wire tension of $12 \mathrm{kgf}$, voltage range $0-100 \mathrm{~V}$, a brass tool of wire $0.25 \mathrm{~mm}$ diameter and deionized water as dielectric fluid is used. The experimental setup is shown in Fig. 2. Mitutoyo Surftest-J210 is used for measuring the average surface roughness. For calculating the MRR, the specimen is weighed before and after machining. The machining time is also noted for each experimental run. The difference in their respective weight divided by their corresponding machining time is recorded as the MRR for that particular experimental run.

Table 1 Chemical Composition of EN-31 Steel

\begin{tabular}{ll}
\hline Element & \% weight \\
\hline Silicon Oxide (SiO) & 25 \\
Chromium (Cr) & 1.46 \\
Carbon (C) & 1.08 \\
Sulphur (S) & 0.015 \\
Phosphorous (P) & 0.022 \\
Nickel (Ni) & 0.33 \\
Molybdenum (Mo) & 0.06 \\
Manganese (Mn) & 0.53 \\
Iron (Fe) & Rest \\
\hline
\end{tabular}

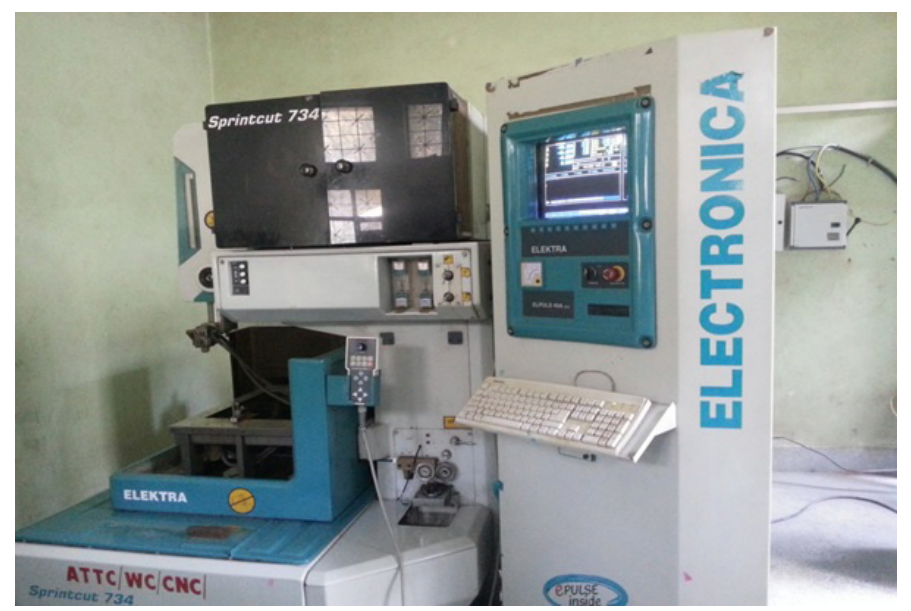

Fig. 2 Experimental Setup

Fig. 1 Workflow of the current research 
Input process parameters selected are- pulse on time, pulse off time, wire tension and servo voltage. Three level for each control factor is used, based on the number of control factors and their levels, the L9 orthogonal array is selected. In a full factorial design with 4 parameters of 3 levels each, the possible experimentation combinations would be $3^{4}$. However by choosing an orthogonal array i.e. the columns for the independent variables are "orthogonal" to one another, the number of experimental trials can be drastically reduced. Moreover, the conclusions are valid over the entire region spanned by the parameters and their corresponding levels. All the considered parameters and their levels are reported in Table 2. Table 3 contains the experiments conducted using the tabulated set of combinations of input parameters, and the output responses surface roughness and material removal rate.

Table 2 Machining parameters and their levels

\begin{tabular}{llll}
\hline \multirow{2}{*}{ Machining Parameters } & \multicolumn{3}{c}{ Level } \\
\cline { 2 - 4 } & 1 & 2 & 3 \\
\hline Pulse on-time $\left(\mathrm{T}_{\text {on }}\right), \mu \mathrm{s}$ & 10 & 15 & 20 \\
Pulse off time $\left(\mathrm{T}_{\text {off }}\right), \mu \mathrm{s}$ & 30 & 35 & 40 \\
Wire Tension $(\mathrm{WT}), \mathrm{kgf}$ & 5 & 6 & 7 \\
Servo Voltage $(\mathrm{SV}), \mathrm{V}$ & 20 & 30 & 40 \\
\hline
\end{tabular}

\section{Methodology}

\subsection{Preference Selection Index}

Preference selection index method was developed by Maniya and Bhatt [10] for solving the multi-criteria decision-making problems. In this approach, it is not necessary to assign a relative importance between attributes. Moreover, there is no requirement of computing weights of attributes involved in decision-making problem in this method [11]. This method is useful when there is conflict in deciding the relative importance of attributes. The various steps involved in PSI technique is described below:
Step 1: Define the objective and identify the attributes and alternatives involved in decision-making problem under consideration. The alternatives here refer to the various set of combinations for different experimental runs.

Step 2: This step involves the construction of a matrix based on all information available that describes the problem attributes. Each row of decision matrix comprises of one alternative and each column to one attribute. Therefore, an element $\mathrm{X}_{\mathrm{ij}}$ of decision matrix $X$ gives the value of a $j^{\text {th }}$ attribute for an $i^{\text {th }}$ experimental run. If the number of alternatives is $M$ and the number of attributes is $\mathrm{N}$, then the decision matrix as $\mathrm{N} x \mathrm{M}$ can be represented as follows:

$$
\left[\begin{array}{cccc}
\mathrm{X}_{11} & \mathrm{X}_{12} & \cdots & \mathrm{X}_{1 \mathrm{~N}} \\
\mathrm{X}_{21} & \mathrm{X}_{22} & \cdots & \mathrm{X}_{2 \mathrm{~N}} \\
\vdots & \vdots & \ddots & \vdots \\
\mathrm{X}_{\mathrm{M} 1} & \mathrm{X}_{\mathrm{M} 2} & \cdots & \mathrm{X}_{\mathrm{MN}}
\end{array}\right]
$$

Step 3: In the multi-attribute decision-making methods, it is required to make the attribute value dimensionless. For this purpose, the attribute values are transferred into 0 and 1. The process of transformation is known as normalization, which is done by attributes.

If the attribute is beneficial type than larger values are desired, which can be normalized as:

$$
N_{i j}=\frac{X_{i j}}{X_{j}^{\max }}
$$

If the attribute is non-beneficial type than smaller values are desired, which can be normalized as:

$$
\mathrm{N}_{\mathrm{ij}}=\frac{\mathrm{X}_{\mathrm{j}}^{\min }}{\mathrm{X}_{\mathrm{ij}}}
$$

Where $\mathrm{X}_{\mathrm{ij}}$ is the attribute measure $(\mathrm{i}=1,2,3, \ldots, \mathrm{n}$ and $\mathrm{j}=1,2 \ldots, \mathrm{m})$. The decision matrix is normalized using Eq. (1)

\begin{tabular}{|c|c|c|c|c|c|c|c|c|c|c|c|c|}
\hline \multirow[b]{2}{*}{$\begin{array}{l}\text { Expt. } \\
\text { No. }\end{array}$} & \multicolumn{4}{|c|}{ Input parameters } & \multicolumn{3}{|c|}{ Surface Roughness $(\mu \mathrm{m})$} & \multicolumn{5}{|c|}{ Material Removal rate } \\
\hline & $\begin{array}{l}\mathrm{T}_{\text {on }} \\
(\mu \mathrm{s})\end{array}$ & $\begin{array}{l}\mathrm{T}_{\text {off }} \\
(\mu \mathrm{s})\end{array}$ & $\begin{array}{l}\text { SV } \\
\text { (V) }\end{array}$ & $\begin{array}{l}\text { WT } \\
\text { (kgf) }\end{array}$ & Trial 1 & Trial 2 & $\begin{array}{l}\text { Avg. } \\
\text { Roughness } \\
\left(\mathrm{R}_{\mathrm{a}}\right)\end{array}$ & $\begin{array}{l}\text { Weight } \\
\text { Before } \\
(\mathrm{gm})\end{array}$ & $\begin{array}{l}\text { Weigh } \\
\text { After } \\
(\mathrm{gm})\end{array}$ & $\begin{array}{l}\text { Cutting } \\
\text { Time } \\
(\mathrm{min}) \\
\end{array}$ & $\begin{array}{l}\text { Material } \\
\text { Removed } \\
(\mathrm{gm})\end{array}$ & $\begin{array}{l}\text { MRR } \\
(\mathrm{gm} / \mathrm{min})\end{array}$ \\
\hline 1 & 110 & 30 & 20 & 5 & 2.6 & 2.561 & 2.6 & 4.89 & 4.45 & 8.56 & 0.44 & 0.0514 \\
\hline 2 & 110 & 35 & 30 & 6 & 2.22 & 2.18 & 2.2 & 4.88 & 4.44 & 9.35 & 0.44 & 0.04705 \\
\hline 3 & 110 & 40 & 40 & 7 & 2.61 & 2.742 & 2.7 & 4.9 & 4.43 & 8.52 & 0.47 & 0.0551 \\
\hline 4 & 115 & 30 & 30 & 7 & 3.61 & 3.565 & 3.6 & 4.91 & 4.45 & 4.42 & 0.46 & 0.10407 \\
\hline 5 & 115 & 35 & 40 & 5 & 2.43 & 1.879 & 2.2 & 4.91 & 4.38 & 5.25 & 0.53 & 0.1009 \\
\hline 6 & 115 & 40 & 20 & 6 & 3.45 & 3.624 & 3.5 & 4.81 & 4.36 & 5.45 & 0.45 & 0.0825 \\
\hline 7 & 120 & 30 & 40 & 6 & 2.77 & 2.652 & 2.7 & 4.91 & 4.42 & 10.41 & 0.49 & 0.04707 \\
\hline 8 & 120 & 35 & 20 & 5 & 2.55 & 2.742 & 2.6 & 4.92 & 4.44 & 8.35 & 0.48 & 0.05748 \\
\hline 9 & 120 & 40 & 30 & 7 & 2.23 & 2.562 & 2.4 & 4.93 & 4.45 & 8.64 & 0.48 & 0.05555 \\
\hline
\end{tabular}
and (2) depending upon the type of data.

Table 3 L9 experimental design with response variables 
Step 4: In this step mean value of the normalized data of every attribute is computed by using the following equation:

$$
\mathrm{N}=\frac{1}{\mathrm{n}} \sum_{\mathrm{i}=1}^{\mathrm{n}} \mathrm{N}_{\mathrm{ij}}
$$

Step 5: In this step, a preference variation value between the values of every attribute is computed using the following equation:

$$
\Phi_{\mathrm{j}}=\sum_{\mathrm{i}=1}^{\mathrm{n}}\left[\mathrm{N}_{\mathrm{ij}}-\mathrm{N}\right]^{2}
$$

Step 6: In this step, deviation in the preference value is computed for every attribute using the following equation:

$$
\Omega_{\mathrm{j}}=\left[1-\Phi_{\mathrm{j}}\right]
$$

Step 7: In this step of PSI method, overall preference value is determined for every attribute using the following equation:

$$
\omega_{\mathrm{j}}=\frac{\Omega_{\mathrm{j}}}{\sum_{\mathrm{j}=1}^{\mathrm{m}} \Omega_{\mathrm{j}}}
$$

Moreover, the total overall preference value of all attribute should be 1 [12].

$$
\sum_{j=1}^{m} \omega_{j}=1
$$

Step 8: Preference selection index is calculated for each alternative using the following equation:

$$
\theta_{\mathrm{j}}=\sum_{\mathrm{j}=1}^{\mathrm{m}} \mathrm{X}_{\mathrm{ij}} \omega_{\mathrm{j}}
$$

Step 9: The value computed for the PSI i.e. $\theta$, should now be used to award the ranking. The ranking should be made as per the descending value of the $\theta$ obtained. The best alternative is the one with the maximum value of $\theta$.

\subsection{TOPSIS}

Technique for Order Preference by Similarity to Ideal Solution (TOPSIS) is a popular multi-criteria decision-making method. It is a versatile approach involving a simple mathematical model. Furthermore, relying on computer support, it is a very suitable practical method [13].

Step 1: Create an evaluation matrix comprising of $m$ alternatives and $\mathrm{n}$ criteria, with the intersection of each alternative and criteria given as $x_{i j}$, we, therefore, have a matrix as given below

$$
\left[\begin{array}{cccc}
x_{11} & x_{12} & \cdots & x_{1 n} \\
x_{21} & x_{22} & \cdots & x_{2 n} \\
\vdots & \vdots & \ddots & \vdots \\
x_{m 1} & x_{m 2} & \cdots & x_{m n}
\end{array}\right]
$$

Step 2: It is to be noted that the given numbers and their matrix must be balanced since the numbers represent different criteria with different measuring units.

Thus the matrix must be normalized to form the matrix $R=\left(r_{i j}\right)_{m \times n}$ using the normalization method

$$
\mathrm{r}_{\mathrm{ij}}=\frac{\mathrm{x}_{\mathrm{ij}}}{\sqrt{\sum_{\mathrm{i}=1}^{\mathrm{m}} \mathrm{x}_{\mathrm{ij}}^{2}}}
$$

Where $i=1,2, \ldots, m$ and $j=1,2, \ldots, n$

The matrix would be given as

$$
\left[\begin{array}{cccc}
r_{11} & r_{12} & \cdots & r_{1 n} \\
r_{21} & r_{22} & \cdots & r_{2 n} \\
\vdots & \vdots & \ddots & \vdots \\
r_{m 1} & r_{m 2} & \cdots & r_{m n}
\end{array}\right]
$$

Step 3: Each criterion must be assigned a weight factor. This weight factor is to be determined objectively by the sum of all weight factors equal to 1 .

A weighted matrix is to be created to form a matrix where

$$
a_{\mathrm{ij}}=\mathrm{w}_{\mathrm{j}} \mathrm{r}_{\mathrm{ij}}=\mathrm{w}_{\mathrm{i}} \frac{\mathrm{x}_{\mathrm{ij}}}{\sqrt{\sum_{\mathrm{i}=1}^{\mathrm{m}} \mathrm{x}_{\mathrm{ij}}^{2}}}
$$

Where $i=1,2 \ldots m$ and $j=1,2 \ldots n$

The matrix would be given as

$$
\left[\begin{array}{cccc}
a_{11} & a_{12} & \cdots & a_{1 n} \\
a_{21} & a_{22} & \cdots & a_{2 n} \\
\vdots & \vdots & \ddots & \vdots \\
a_{m 1} & a_{m 2} & \cdots & a_{m n}
\end{array}\right]
$$

Step 4: Determine the positive ideal solution $\left(A_{j}^{+}\right)$and the negative ideal solution $\left(A_{j}^{-}\right)$alternative

The coordinates for $\left(A_{j}^{+}\right)$of positive ideal solution $A^{+}=$ $\left(A_{1}^{+}, A_{2}^{+} \ldots A_{n}^{+}\right)$are chosen using the formula

$$
A_{j}^{+}=\left\{\begin{array}{l}
\max a_{i j} \text { for } j=1, \ldots . k \\
\min a_{i j} \text { for } j=k+1, \ldots n
\end{array}\right.
$$

The coordinates for $\left(A_{j}^{-}\right)$of negative ideal solution $A^{-}=$ $\left(A_{1}^{-}, A_{2}^{-} \ldots A_{n}^{-}\right)$are chosen using the formula

$$
A_{j}^{-}=\left\{\begin{array}{l}
\min a_{i j} \text { for } j=1, \ldots . k \\
\max a_{i j} \text { for } j=k+1, \ldots n
\end{array}\right.
$$

Step 5: Calculate the distance between the target alternative $i$ and the negative ideal solution $A^{-}$is given by

$$
\mathrm{S}^{-}=\sqrt{\sum_{\mathrm{j}=1}^{\mathrm{n}}\left(a_{\mathrm{ij}}-\mathrm{A}_{\mathrm{j}}^{-}\right)^{2}}
$$

Similarly, calculate the distance between the target alternative $i$ and the positive ideal solution $A^{+}$is given by

$$
\mathrm{S}^{+}=\sqrt{\sum_{\mathrm{j}=1}^{n}\left(a_{\mathrm{ij}}-\mathrm{A}_{\mathrm{j}}^{+}\right)^{2}}
$$

Step 6: Calculate the relative distance of the points from the ideal solution using the formula

$$
\mathrm{S}=\frac{\mathrm{S}^{-}}{\mathrm{S}^{+}+\mathrm{S}^{-}}
$$


Step 7: Rank the $\mathrm{S}$ in the descending order with the highest valued criteria/option/alternative being an ideal one.

\section{Results and Discussions}

Wire electrical discharge machining (WEDM) is an important non-conventional machining process capable of accurately machining parts of hard materials with complex shapes. Rough cutting operation in WEDM is treated as a challenging one because improvement of more than one machining performance measures viz. metal removal rate (MRR) and surface finish (SF) are needed to obtain a precision work. In this work both PSI and TOPSIS are used to optimize the process parameters such as Pulse on Time $\left(\mathrm{T}_{\text {on }}\right)$, Pulse off Time $\left(\mathrm{T}_{\text {off }}\right)$, Servo Voltage $(\mathrm{SV})$ and the wire tension (WT). Also, a comparative analysis is done by using both the techniques and is given below. Based on the regression analysis the following first-order empirical equations are generated,

$R_{a}=1.85+0.0067 \mathrm{~T}_{\text {on }}-0.0352 \mathrm{~T}_{\text {off }}-0.0310 \mathrm{SV}+0.379 \mathrm{WT}$

$$
\begin{aligned}
M R R & =0.044+0.00022 \mathrm{~T}_{\text {on }}-0.00037 \mathrm{~T}_{\text {off }} \\
& +0.00017 \mathrm{SV}+0.0009 \mathrm{WT}
\end{aligned}
$$

Fig. 3 shows a comparison between the experimental and the predicted responses based on the above equations. It is seen that the variation between the experimental and the regression equation predictions are within the permissible limit.

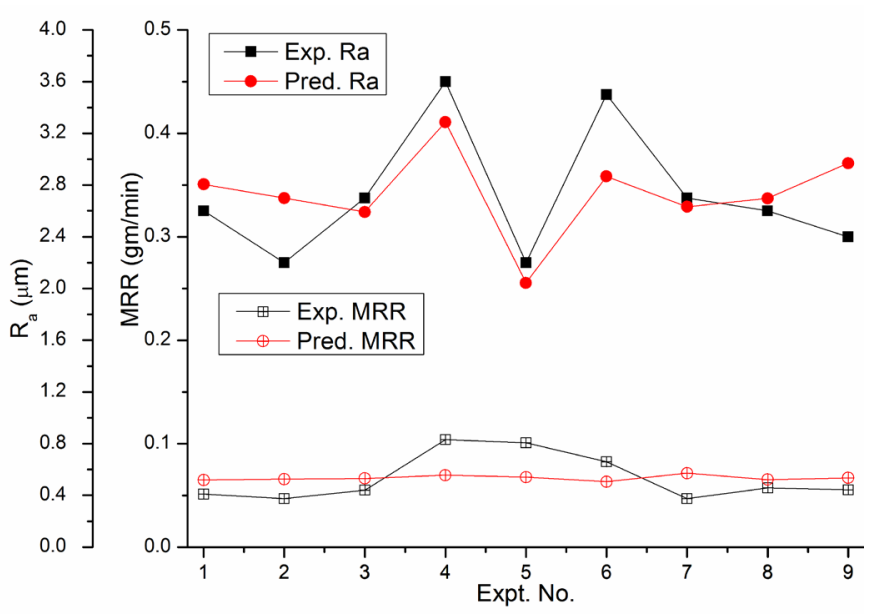

Fig. 3 Comparison between experimental and predicted responses

\subsection{Preference Selection Index}

The objective is to select the optimal set of process parameters to optimize the response i.e. surface roughness and material removal rate while machining EN31 Tool Steel in WEDM. In the current problem, the surface roughness $\left(R_{a}\right)$ is non-beneficial type as the lower value of surface roughness is required; hence, its value is normalized using Eq. (3). MRR is beneficial type as the higher value of MRR is needed; hence, it is normalized using Eq. (2). The mean values of the normalized data of the attribute
Surface Roughness $\left(\mathrm{R}_{\mathrm{a}}\right)$ and Material Removal Rate (MRR) are computed using Eq. (4). The mean value obtained from above equation are $\mathrm{N}_{\mathrm{Ra}}=0.8157$ and $\mathrm{N}_{\mathrm{MRR}}=0.64199$. The preference variation value obtained using the Eq. (5) are $\Phi_{\mathrm{Ra}}=0.3076$ and $\Phi_{\text {MRR }}=0.38491$. Deviation in preference value obtained using Eq. (6) is $\Omega_{\mathrm{Ra}}=0.6924$ and $\Omega_{\mathrm{MRR}}=0.61509$. The overall preference is computed using Eq. (7) are $\omega_{\mathrm{Ra}}=0.529$ and $\omega_{\mathrm{MRR}}=$ 0.4704. An optimal parameters selection index of WEDM for every alternative computed using Eq. (9) is illustrated in Fig. 4. The ranking order for different alternatives as per preference selection index value is Exp. $5>4>2>9>6>8>3>1>7$

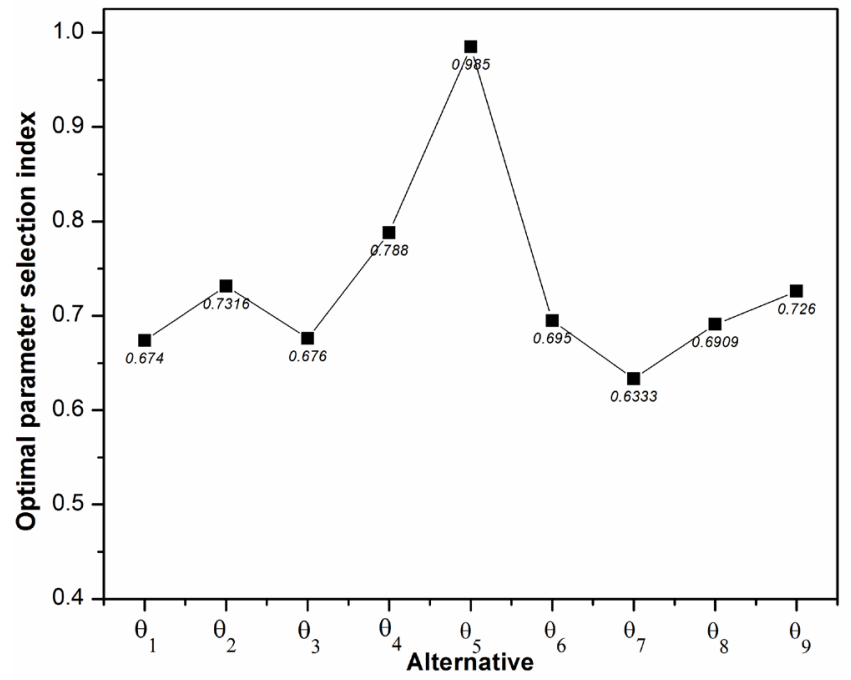

Fig. 4 Optimal set of process parameters by PSI

\subsection{Ranking based on TOPSIS}

As per the problem, the matrix formulated consists of nine alternatives (Taguchi orthogonal array) and two performance criteria i.e. surface roughness and MRR. The evaluation matrix is normalized by using Eq. (11). Weighted matrix is obtained through multiplication of individual weights of performance measures with the normalized data. In this process, both surface roughness, as well as MRR, being a critical response, weightage value of 0.5 each is being assigned to both. The weighted matrix is thus obtained by using Eq. (12). However, for the sake of brevity, the weighted matrix is not presented here. Ideal positive solution $\left(\mathrm{A}^{+}\right)$and Ideal negative solution $\left(\mathrm{A}^{-}\right)$is obtained using the criteria of higher the better and lower the better respectively. The values obtained are Ideal positive solution $\mathrm{A}^{+}=0.12995$ (minimum value for $\mathrm{R}_{\mathrm{a}}$ ) and 0.24695 (maximum value for $\mathrm{MMR}$ ); Ideal negative solution $\mathrm{A}^{-}=0.2162$ and 0.1117 (maximum value for $\mathrm{R}_{\mathrm{a}}$ ) and 0.24695 (minimum value for MMR). The distance of target alternative from negative ideal solution and the positive ideal solution is obtained using the Eq. (15) and Eq. (16) respectively. The relative closeness to the ideal solution obtained using Eq. (17) is presented in Fig. 5. The ranking order for different alternatives as per TOPSIS is given below Exp. $5>4>6>9>2>8>3>1>7$. 


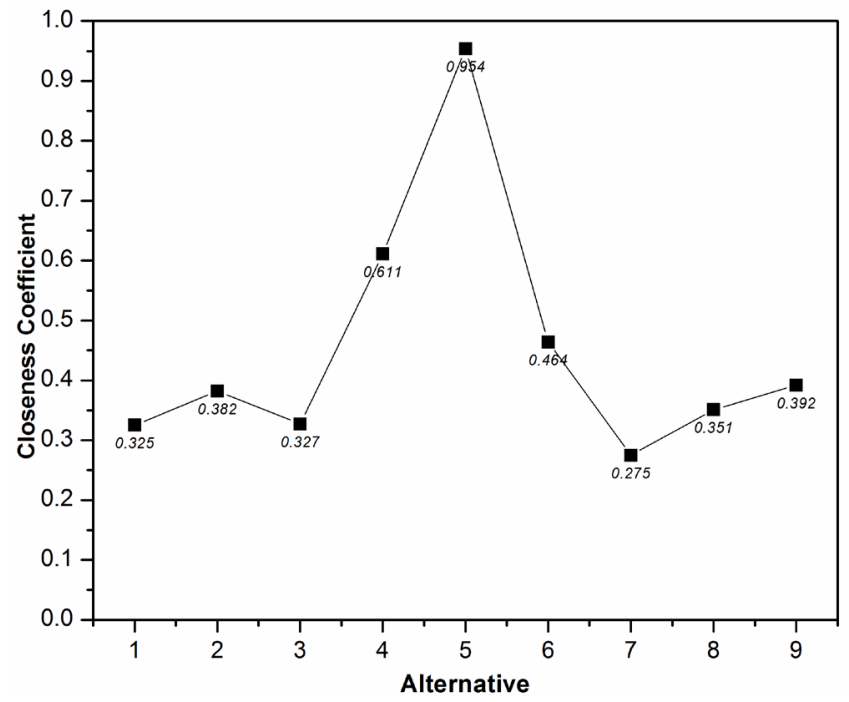

Fig. 5 Closeness coefficient of each experiment by TOPSIS

\section{Conclusion}

The present work deals with studying the effect and optimization of the input parameters, namely Pulse on Time $\left(\mathrm{T}_{\mathrm{on}}\right)$, Pulse Off Time $\left(\mathrm{T}_{\text {off }}\right)$, Servo Voltage (SV) and the Wire tension (WT), against the Output Responses, namely surface roughness and metal removal rate. Experiments are conducted based upon the L16 Orthogonal array. The result showed that a single parameter alone does not have a significant influence on the output responses. The quality of the output responses depends on the combination of the various set of input parameters. The best set of combination from the chosen input parameters for machining of EN31 Tool Steel by Wire EDM Process was found to bePulse on Time $\left(\mathrm{T}_{\mathrm{on}}\right)-15 \mu \mathrm{s}$, Pulse off Time $\left(\mathrm{T}_{\text {off }}\right)-35 \mu \mathrm{s}$, Servo Voltage (SV) 40V and the Wire tension (WT)-5kgf from both PSI as well as TOPSIS optimization techniques.

\section{References}

[1] Gowdy, G. H., Reddy, M. G., Sreenivasulu, B., Ravuri, M. "Multi Objective Optimization of Process Parameters in WEDM during Machining of SS304." Procedia Materials Science. 5, pp. 1408-1416. 2014. https://doi.org/10.1016/j.mspro.2014.07.459

[2] Tilekar, S., Das, S. S., Patowari P. K. "Process Parameter Optimization of Wire EDM on Aluminum and Mild Steel by Using Taguchi Method." Procedia Materials Science. 5, pp. 2577-2584. 2014. https://doi.org/10.1016/j.mspro.2014.07.518

[3] Dabade, U. A., Karidkar, S. S. "Analysis of Response Variables in WEDM of Inconel 718 Using Taguchi Technique." Procedia CIRP. 41, pp. 886-891. 2016 . https://doi.org/10.1016/j.procir.2016.01.026

[4] Patel, V., Patel, J. D., Maniya, K. D. "Selection of the wire cut electrical discharge machining process parameters using AHP/TOPSIS method." International Journal of Advance Engineering and Research Development. 1, 2014.
[5] Saha, P.,Singha, A., Pal, S. K., Saha, P. "Soft computing models based prediction of cutting speed and surface roughness in wire electrodischarge machining of tungsten carbide cobalt composite." The International Journal of Advanced Manufacturing Technology. 39(1-2), pp. 74-84. 2008.

https://doi.org/10.1007/s00170-007-1200-z

[6] Patel, J. D., Maniya, K. D. "Application of AHP/MOORA Method to Select Wire Cut Electrical Discharge Machining Process Parameter to Cut EN31 Alloys Steel with Brasswire." Materials Today: Proceedings. 2(4), pp. 2496-2503. 2015.

https://doi.org/10.1016/j.matpr.2015.07.193

[7] Ardeshir, A., Amiri, M., Ghasemi Y., Errington, M. "Risk assessment of construction projects for water conveyance tunnels using fuzzy fault tree analysis." International Journal of Civil Engineering. 12(4), pp. 396412. 2014.

[8] Ardeshir, A., Maknoon, R., Rekab Islami Zadeh, M., Jahantab, Z. "HSE risks assessment in urban high-rise construction using Fuzzy Approach." Journal of Health and Safety at Work. 5(2), pp. 1-12. 2015.

[9] Ardeshir, A., Mohseni, N., Behzadian K., Errington, M. "Selection of a bridge construction site using fuzzy analytical hierarchy process in geographic information system" Arabian Journal for Science and Engineering. 39(6), pp. 4405-4420. 2014. https://doi.org/10.1007/s13369-014-1070-2

[10] Maniya K., Bhatt, M. G. "A selection of material using a novel type decision-making method: preference selection index method." Materials \& Design. 31(4), pp. 1785-1789. 2010.

https://doi.org/10.1016/j.matdes.2009.11.020

[11] Ezatpour, H. R., Parizi, M. T., Sajjadi, S. A., Ebrahimi, G. R., Chaichi, A. "Microstructure, mechanical analysis and optimal selection of 7075 aluminum alloy based composite reinforced with alumina nanoparticles." Materials Chemistry and Physics. 178, pp. 119-127. 2016. https://doi.org/10.1016/j.matchemphys.2016.04.078

[12] Singh, T., Patnaik, A., Gangil B., Chauhan, R. "Optimization of triboperformance of brake friction materials: effect of nano filler." Wear. 324, pp. 10-16. 2015.

https://doi.org/10.1016/j.wear.2014.11.020

[13] Shivakoti, I., Shivakoti, I., Pradhan, B. B., Diyaley, S., Ghadai, R. K., Kalita, K. "Fuzzy TOPSIS-Based Selection of Laser Beam Micro-marking Process Parameters." Arabian Journal for Science and Engineering. 1-7. 2017.

https://doi.org/10.1007/s13369-017-2673-1 